\title{
DOI: https://doi.org/10.24297/jac.v16i0.8248
}

\section{Oxidative Study of Benzaldehyde By Isoqauinolinium Bromo chromate}

\author{
Arun Kumar Dwivedi ${ }^{1}$, Arvind Prasad Dwivedi ${ }^{2}$ and K. N. Sharma ${ }^{3}$ \\ 1Department of Chemistry, A.P.S. University, Rewa-486003 (M.P.) India \\ ${ }^{2}$ Department of Chemistry, Govt.Sanjay Gandhi Smrati Auto.P.G.College Sidhi M.P. \\ ${ }^{3}$ Department of Chemistry, Govt. Girls P.G. College Rewa-486001 (M.P.) India
}

\begin{abstract}
:
The kinetics analysis of the oxidative reaction between benzaldehyde and oxidant is quinolinium Bromo chromate was reported in aqueous $40 \%$ acetic acid medium at $313 \mathrm{~K}$. The rate of reaction varies first-power of [IQBC] and $\left[\mathrm{H}_{2} \mathrm{SO}_{4}\right]$, whereas fractional-order kinetics was observed for benzaldehyde. The rate constant gradually increases with decrease in dielectric constant of the medium. The neutral salt does not alter the rate. The metal cations $\left(\mathrm{Cu}^{++}\right)$slightly accelerate the rate of oxidation when added to reaction mixture. The study rules out the participation of keto form of substrate in complex formation. Benzoic acid was identified as the end-product in stoichiometrically 1:1 based mechanism. The rate law was derived in accordance with the kinetic results.
\end{abstract}

Key words: Kinetics, Stoichiometry, Excellent, Photosensitivity, Error.

\section{Introduction}

Several chromium(VI) compounds have been introduced in literature as oxidizing agent, capable of oxidizing almost every oxidizing functional group. However, such oxidant possesses high acidity, photosensitivity, instability take long reaction time and need for large excess of reagent. In order to avoid above difficulties, recently an excellent Is quinolinium Bromo chromate oxidant has been inducted in literature of kinetics for oxidation of anilines, ${ }^{1}$ phenols, ${ }^{2}$ alcohols, ${ }^{3,4}$ and ketones. ${ }^{5}$ In proposed study, the benzaldehyde containing carbonyl group exhibited a variety of chemical reactions with oxidizing reagents viz. $\mathrm{SeO}_{2}{ }^{6} \mathrm{BAT}_{1}{ }^{7} \mathrm{NBSA}_{1}^{8}{ }^{8}$ acid bromate ${ }^{9}$ and $\mathrm{NCSA}^{10}$ etc. which results different mechanism.

The controversy always persists about the attack of $\mathrm{H}_{2} \mathrm{CrO}_{4}$, active species of IQBC at enolic or keto or gemdiol position of benzaldehyde. In order to remove this ambiguity, the task of oxidation of this substrate with IQBC was chosen for investigation.

\section{Experimental}

All solvents and chemicals used in the kinetic study were of analytical grade. A fresh standard solution of oxidant IQBC was used before initiation of experiments. The substrate (benzaldehyde) solution was prepared in requisite amount of acetic acid. The solution of $\mathrm{H}_{2} \mathrm{SO}_{4}$ was made in distilled water and standardized by $\mathrm{NaOH}$ which was in turn standardized by standard solution of oxalic acid using phenolphthalein as indicator. All other useful solutions were prepared and wherever necessary were standardized by different methods.

\section{Procedure}

The kinetic investigation was initiated by mixing appropriate volume of IQBC, benzaldehyde acetic acid, and $\mathrm{H}_{2} \mathrm{SO}_{4}$ at experimental temperature $313 \mathrm{~K}$ in reaction vessel maintain in thermostat with high accuracy. The reaction velocity was measured from the concentration of unreacted IQBC left, at different intervals of time. The study was followed by removing immediately $2 \mathrm{ml}$ of reaction mixture quenched with ice cold water and 
estimated volumetrically by titrating against standard solution of $\mathrm{Na}_{2} \mathrm{~S}_{2} \mathrm{O}_{3}{ }^{11}$ using starch as an indicator. The rate constant $(\mathrm{k})$ was evaluated by graphical and other methods. Ostwald's dilution method was also used to curb the possible error arises due to side reaction occurring if any in the reaction. The results were reproducible within an error of $\pm 4 \%$ in duplicate runs.

The trapping method shows inertness for the presence of free radicals in the reaction mixture. Benzoic acid was formed as the reaction product of benzaldehyde, was detected by determining its melting point and also forming its 2,4-DNP derivative.

\section{Results and Discussion}

An attempt has been made by performing a number of experiments with varying [IQBC] but at fixed concentrations of all or reactants and temperatures (Table1). The value of $(-\mathrm{dc} / \mathrm{dt})$ has been calculated by slope of tangential slope drawn on curve obtained on plotting remaining [IQBC] (Fig.1). The - dc/dt of reaction was found to vary as first-power of [IQBC]. In the next set of experiment, the study was performed at different [benzaldehyde] under fixed conditions. Overall studies indicate fractional-order kinetics with respect to benzaldehyde at higher concentrations. The effect of $\left[\mathrm{H}_{2} \mathrm{SO}_{4}\right]$ on reaction has been analysed at different $\left[\mathrm{H}_{2} \mathrm{SO}_{4}\right]$, keeping concentrations of or reactions constant at $313 \mathrm{~K}$.

\section{Table 1 : Effect of concentration of oxidant (IQBC) on rate}

$\left[\mathrm{C}_{6} \mathrm{H}_{5} \mathrm{CHO}\right]=3.33 \times 10^{-2}\left(\mathrm{~mol} \mathrm{dm}^{-3}\right)$ ；

$\left[\mathrm{H}_{2} \mathrm{SO}_{4}\right]=2.00 \times 10^{-3}\left(\mathrm{~mol} \mathrm{dm}^{-3}\right)$;

$\mathrm{CH}_{3} \mathrm{COOH}-\mathrm{H}_{2} \mathrm{O}=40 \%(\mathrm{v} / \mathrm{v})$;

Temp. $=313 \mathrm{~K}$

\begin{tabular}{|c|c|c|}
\hline S. No. & $\begin{array}{l}{[\mathrm{IQBC}] \times 10^{3}} \\
\left(\mathrm{~mol} \mathrm{dm} \mathrm{dm}^{-3}\right)\end{array}$ & k $10^{4}\left(s^{-1}\right)$ \\
\hline 1. & 1.25 & 1.81 \\
\hline 2. & 2.00 & 1.84 \\
\hline 3. & 2.50 & 1.82 \\
\hline 4. & 3.33 & 1.89 \\
\hline 5. & 4.00 & 1.90 \\
\hline 6. & 5.00 & 1.87 \\
\hline
\end{tabular}


It is evident from summarized data that the values of $(-\mathrm{dc} / \mathrm{dt})$ increases linearly with increase in $\left[\mathrm{H}^{+}\right]$

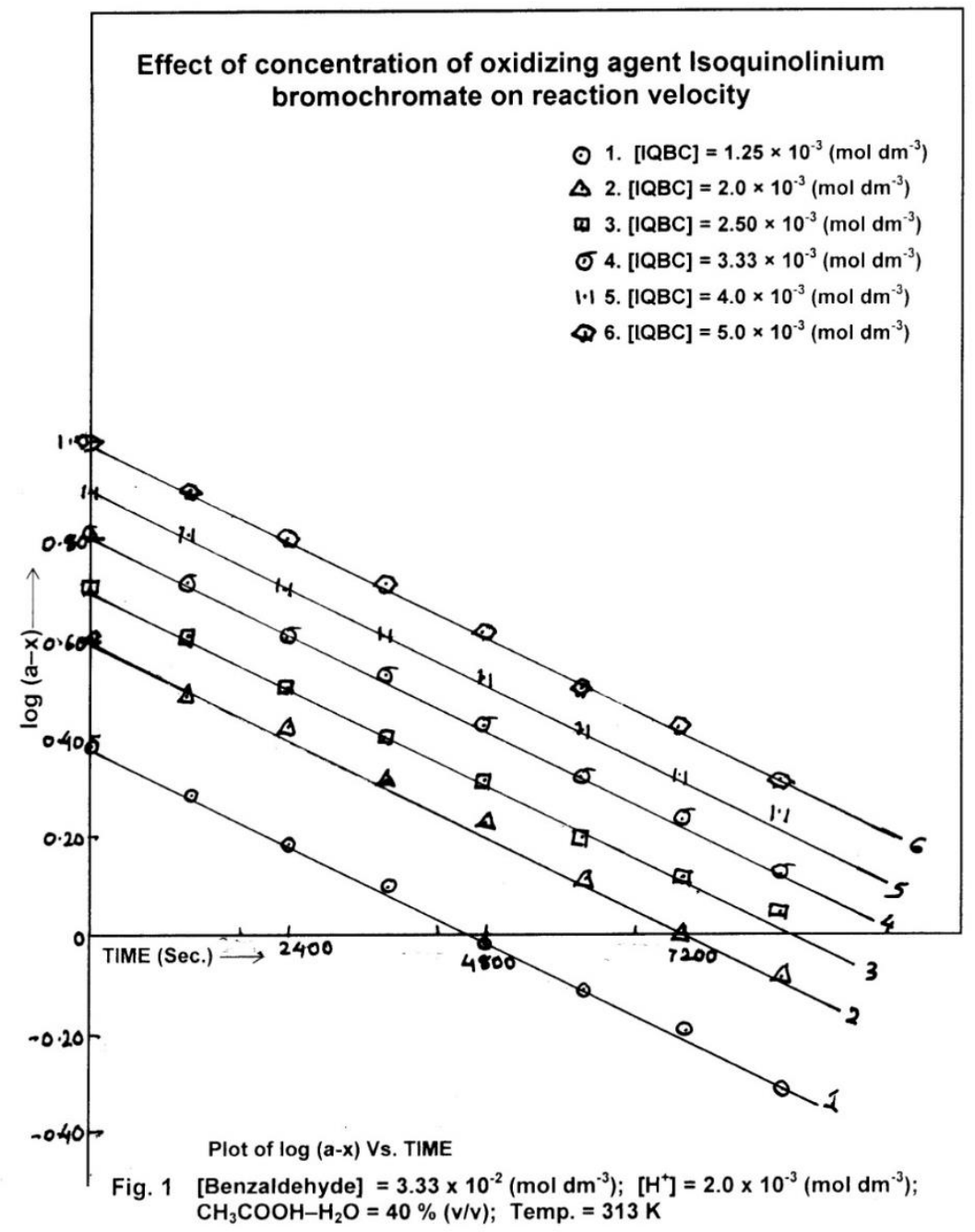

for benzaldehyde (Table 2). This observation has been confirmed by plotting $(-\mathrm{dc} / \mathrm{dt})$ values against $\left[\mathrm{H}^{+}\right]$with unit slope (Fig.2).

\section{Table 2 : Effect of concentration of acid on rate}

$\left[\mathrm{C}_{6} \mathrm{H}_{5} \mathrm{CHO}\right]=3.33 \times 10^{-2}\left(\mathrm{~mol} \mathrm{dm}^{-3}\right) ;$

$\left[\mathrm{H}_{2} \mathrm{SO}_{4}\right]=2.50 \times 10^{-3}\left(\mathrm{~mol} \mathrm{dm}^{-3}\right) ;$

$\mathrm{CH}_{3} \mathrm{COOH}-\mathrm{H}_{2} \mathrm{O}=40 \%(\mathrm{v} / \mathrm{v})$;

Temp. $=313 \mathrm{~K}$

\begin{tabular}{|c|c|c|}
\hline S. No. & $\begin{array}{l}10^{3} \times\left[\mathrm{H}_{2} \mathrm{SO}_{4}\right] \\
\left(\mathrm{mol} \mathrm{dm}^{-3}\right)\end{array}$ & $10^{4} \mathrm{k}^{\left(\mathrm{s}^{-1}\right)}$ \\
\hline 1. & 1.00 & 1.31 \\
\hline 2. & 2.00 & 1.89 \\
\hline 3. & 2.50 & 2.63 \\
\hline 4. & 4.00 & 3.94 \\
\hline
\end{tabular}




\begin{tabular}{|l|l|l|}
\hline 5. & 5.00 & 5.22 \\
\hline
\end{tabular}

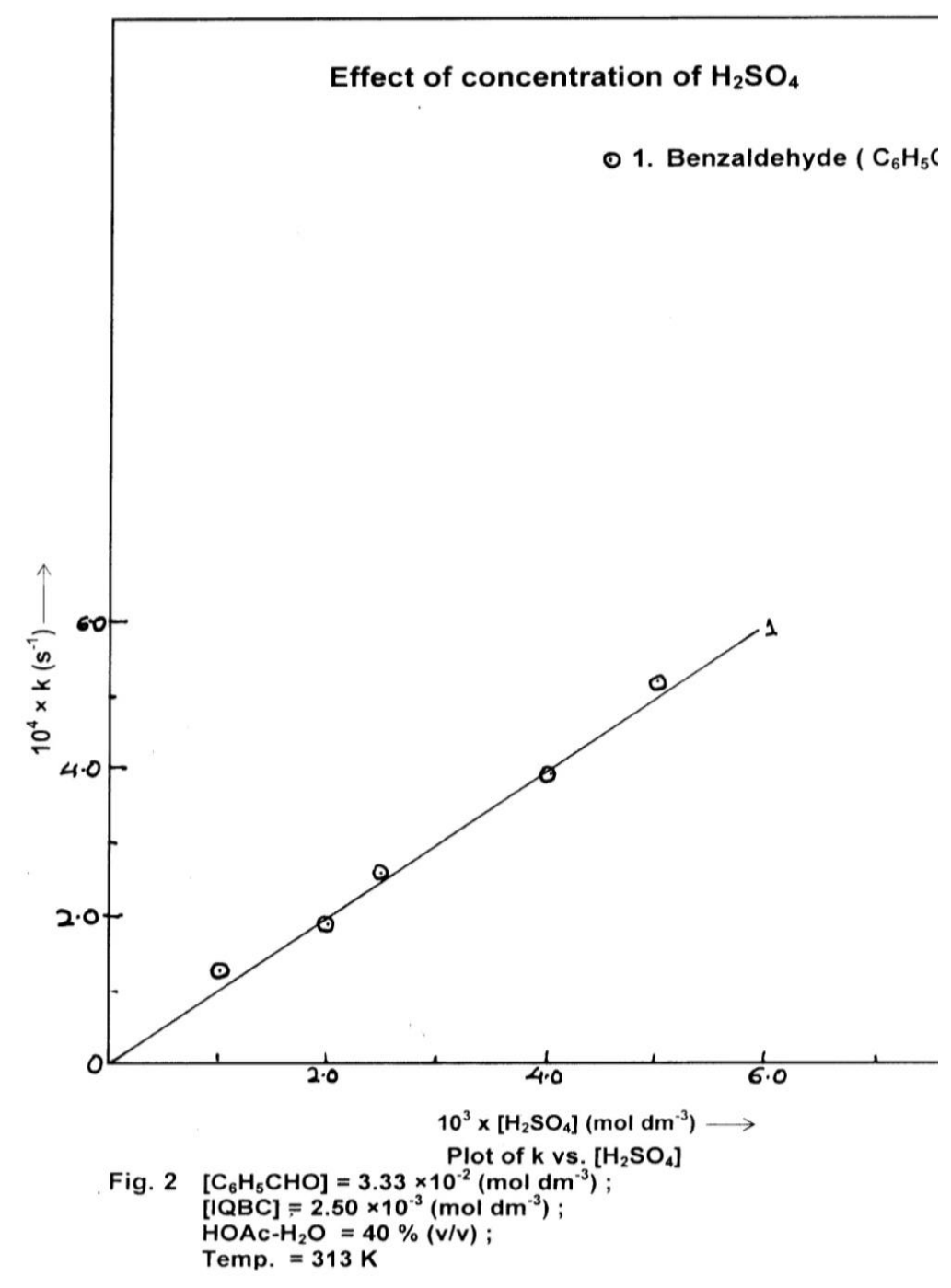


The rate of reaction steadily increases with rise in percentage composition of $\mathrm{CH}_{3} \mathrm{COOH}-\mathrm{H}_{2} \mathrm{O}(\mathrm{v} / \mathrm{v})$, resulting positive intercept/slope for the Amis plot of log k vs. D-1/ $2 \mathrm{D}+1$ has been found to be linear in accordance with the Kirkwood theory of dipole-dipole type reaction. The salt effect and ionic strength of the reaction was varied by the addition of $\mathrm{KCl}$. It was found that they have no impact on reaction rate. The addition of catalyst $\mathrm{Cu}^{++}$ions in reaction had shown acceleration in oxidation reaction.

The stoichiometric measurement ${ }^{12,13}$ has indicated 1:1 mole ratio for benzaldehyde and oxidant (IQBC) as shown in equation (1).

$\phi \mathrm{HCrO}_{3} \mathrm{Br}+\mathrm{C}_{6} \mathrm{H}_{5} \mathrm{CHO}+\mathrm{H}_{2} \mathrm{O} \rightarrow \mathrm{C}_{6} \mathrm{H}_{5} \mathrm{COOH}+\phi+\mathrm{H} \mathrm{Br}+\mathrm{H}_{2} \mathrm{CrO}_{3}$

where, $\phi=$ is quinoline.

\section{Mechanism}

Considering the kinetic results as briefed above, a plausible mechanism for the aforementioned reaction might be illustrated as :

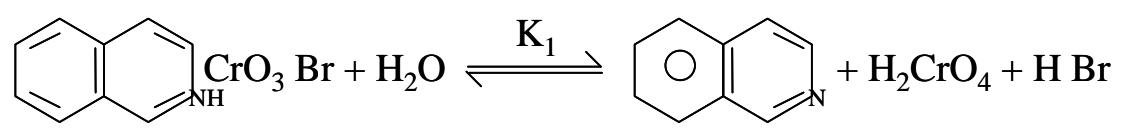

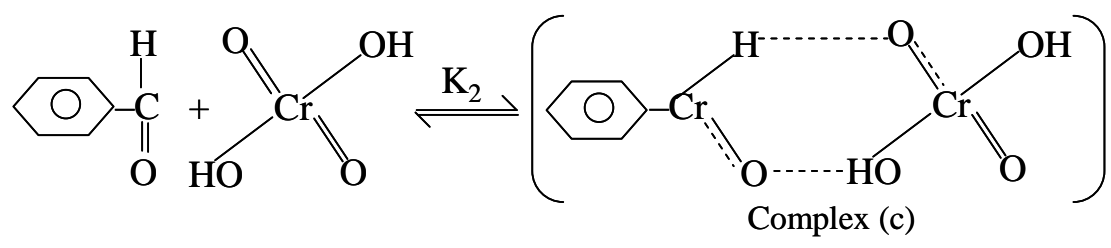

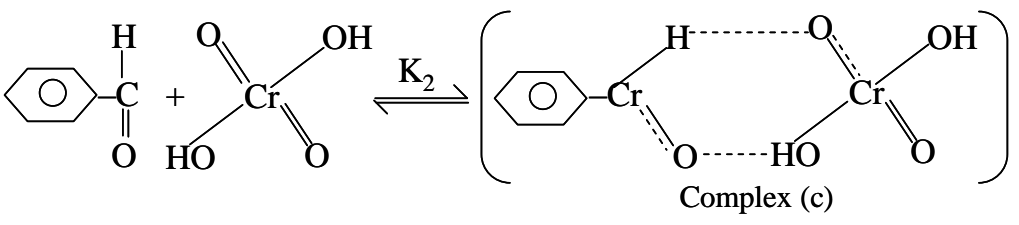

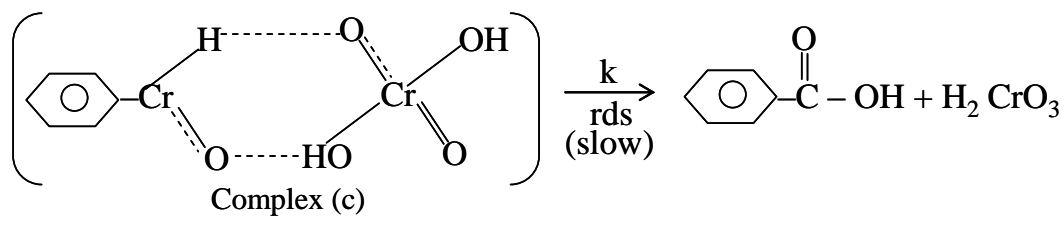

$$
\mathrm{H}_{2} \mathrm{CrO}_{3} \stackrel{\text { fast }}{\longrightarrow} \mathrm{H}_{2} \mathrm{O}+\mathrm{CrO}_{2}
$$

The prime active species $\mathrm{H}_{2} \mathrm{CrO}_{4}$ of oxidant, IQBC attacks the keto form of substra (6) tep to form non-rigid intermediate complex of the structure shown above in the transition stat $\epsilon$, venly uistavie and lasted not very long time decomposes into products.

Applying approximation method at steady state condition, the final rate law was formulated as : 


$$
\mathrm{k}_{\mathrm{obs}}=\frac{\mathrm{k} \mathrm{K}_{1} \mathrm{~K}_{2}[\mathrm{~S}]\left[\mathrm{H}^{+}\right]}{[\mathrm{IQ}] \mathrm{K}_{1}+\mathrm{K}_{1} \mathrm{~K}_{2}[\mathrm{~S}]}
$$

Imposing the condition of valid assumptions at low [substrate], equation (7) reduces to

$\mathrm{k}_{\mathrm{obs}}=\mathrm{k}$

and at higher concentration of substrate on transforming equation (7)

$$
\frac{1}{\mathrm{k}_{\mathrm{obs}}}=\frac{[\mathrm{IQ}] \mathrm{k}_{1}+\mathrm{K}_{1} \mathrm{~K}_{2}[\mathrm{~S}]}{\mathrm{K}_{1} \mathrm{~K}_{1} \mathrm{k}[\mathrm{S}]\left[\mathrm{H}^{+}\right]}
$$

The rate equation obtained is in good agreement with the experimental data. The kinetic results suggested the existence of binary complex which is strongly favoured by a double reciprocal plot $\left(\mathrm{k}^{-1}\right.$ obs vs. $\left.[\mathrm{S}]^{-1}\right)$ with a positive slope on $\mathrm{Y}$-axis showing fractional-order kinetics for benzaldehyde. Various Arrhenius parameters were determined at different temperatures for the substrate.

\section{References}

1. Patwari, S.B., Khansole, S.V. and Vibhute, Y.B., Bulletric of the catalysis Society of India, 2009, 8, 114120.

2. Patwari, S.B., Khansole, S.V. and Vibhute, Y.B., Chinese Chemical Letters, 2009, 20(3), 256-260.

3. Patwari, S.B., Khansole, S.V. and Vibhute, Y.B., J. Iran. Chem. Soc., 2009, 6(2), 399-404

4. Patwari, S.B., Khansole, S.V. and Vibhute, Y.B., J. Indian Chem. Soc., 2009, 86(12), 1343-1346.

5. Trivedi, Khushboo and Khan, M.U., Elec. J. Adv. Research, 2017 (32), 113-121.

6. Tiwari, S., Khan, M.U. Tiwari, B.M.L., Tiwari, K.S. and Valechha, N.D., Oxid. Common., 1999, 22, No.3, 416-423.

7. Singh, B., Singh, D., Chand, R. and Singh, A.R., J. Indian Chem. Soc., 1987, 64, 741.

8. Mohan, K.V., Raghunath Rao, P., and Sundaram, E.V., J. Indian Chem. Soc., 1984, 61, 225.

9. Krishnamurti, M., SanjeevaReddy, C.H., and Sundarma, E.V., J. Indian Chem. Soc., 1989, 28A, 288.

10. Khan, S., Khan, M.U., Singh, S.K., Gupta, H.D., and Singh, P.K., Asian J. Chem., 2007, 15 (2), 5267-5270.

11. Radhakrishnamurti, P.S., Rath, N.B. and Pandey, R.K.: Indian J. Chem., 1988, 27, 963.

12. Singh, S.K.R., Gupta, O.P. Khan, M.U., Gupta, H.D., and Singh, S.K., Oxid. Commun. 2010, 33, No.4, $891-$ 897.

13. Alhaji, N.M.I., and Sofia, S. Lawrence, Mary, E. J. Chem., 2011, 8(4), 1472, 1477. 